\title{
The Effect of Food Quality on Customer Choice of Dining Destination in Kenya
}

\author{
Robert Orenge Ondara ${ }^{*}$ \\ Erick V.O Fwaya ${ }^{2}$ \\ Bichage Gesage ${ }^{3}$ \\ Dunstan Kambaga ${ }^{3}$ \\ School of Hospitality and Human, Ecology, Technical University of Kenya, Kenya ${ }^{*}$ \\ School of Hospitality and Tourism Studies, Maasai Mara University, Kenya ${ }^{2}$ \\ School of Business, Karatina University, Kenya ${ }^{3}$ \\ School of Business and Management Studies, Technical University of Kenya ${ }^{4}$ Kenya
}

\begin{abstract}
Food quality has received attention by hoteliers because of its effect on customer choice of dining destination in Kenya. Achieving food quality (FQ) management standards across the hospitality industry presents a challenge for governments worldwide and Kenya in particular. The specific objective of this study was to determine the effect of food quality on customer's choice of dining destination in Kenya. The study adopted a cross-sectional descriptive survey design where 1058 guests were sampled based on 2016 data provided by the Kenya Tourism Board on bed occupancy calculated at 49\%. Additionally, 54 Hotel staffs (managers and sous chef) were randomly selected from 4-star and 5-star hotels in Nairobi and Mombasa. Self-administered questionnaires and interview schedules were employed to collect data. Qualitative data collected through interview schedules was analyzed thematically. Quantitative data collected was coded in SPSS version 21 and analyzed using multiple regression. The results revealed that the top three aspects that were considered to be highly important while referring to food quality included taste $(n=426)$, freshness $(n=393)$ and good condition $(n=330)$. Results of the study indicated that the odds ratio of a restaurant with good food quality being selected over that with average food quality was 3.387 to 1 , while the odds of a restaurant with poor food quality had the odds of 0.091 to 1 of being selected over a restaurant with average food quality. The overall effect of food quality was found to be significant since the corresponding -value for was 0.025 , which was less than 0.05 (P-value $=0.005<0.05)$.
\end{abstract}

Keywords: Food Quality, Food Safety, Monitoring, Customer Choice, Dining Destination

Corresponding author: Robert Orenge Ondara; E-mail: robertondara@yahoo.com DOI: https://doi.org/10.37227/ITHJ-2021-03-722

\section{Introduction}

The demand for high quality food has constantly increased during recent decades, As the core product of commercial food service, food quality plays a pivotal role in the dining 
experience and is critical to the success of the restaurants at tourist destinations (Bujisic, Hutchinson, and Parsa, 2014; Bae, Slevitch and Tomas, 2018).

Despite this importance, previous studies presented mixed findings about the impact of food quality and dining revisit intention. Wu et al., (2018) argued that food quality positively affects customers' dining revisit, while Caber et al., (2018) reported that the effect of food quality on customers' dining satisfaction is gradually reducing. Ha, and Jang (2013) in his study on determinants of diner's variety seeking intentions recommended that the competitive capability of a hotel is created as a result of its quality practices. The study however failed to explore the specific quality management practices that influence organizations performance in Hospitality destinations. A study by Arendt, Paez and Strohbehn (2013), noted that, many food establishments are currently struggling to embrace effective quality management systems in order to meet and exceed customers' demands in the global market. The study however failed to explain the major challenges affecting implementation of quality management realization in an effort to increase organization performance.

As a globalized sector, the Hospitality industry's inter-destination competition is very high and this phenomenon is caused by amongst other things, FQ which hotels find themselves to favorably compete internationally. This in turn results in increased international competition not only between destinations but also between Hotel establishments (Burusnukul, Binkley \& Sukalakamala, (2011).

Previous studies conducted in Africa (e.g. Ohiokpehai, 2003; Omemu \& Aderoju, 2008) has focused mainly on food handling by street vendors but did not adequately seek to understand how consumers choose their destination. Tunalioglu et al., 2012; Validi et al., 2014; Darkow et al., 2015), confirms that governments in Africa face a number of obstacles in implementing FQ compliance standards. The study also established that the level of awareness among food producers is negligible (World Bank, 2015). This aggravates the uncertainty and information asymmetry in the supply chain and makes monitoring of FQ more difficult (Validi al., 2014; Darkow et al., 2015). Other researchers (e.g. Michie, Sniehotta \& Webb, 2010), have revealed that there has been a change in consumer purchase behavior towards food safety and quality and other products leading to attitude -behavior- gap.

In Kenya, while the objective of FQ control remains constant, effective FQ control is undermined due to the existence of fragmented legislation, multiple jurisdictions, and weaknesses in surveillance, monitoring and enforcement (Oloo, 2010). Nevertheless, Kenya is still at its infancy stage with various challenges such as lack of transparency, selfdiscipline in food handling and unwillingness to cooperate between raw material suppliers. Lack of monitoring and detection system also makes it difficult to regulate the industry (Zhang et al., 2015).

According to Chen, Wang, \& Song, (2015), the responsibility for food quality control in most countries is shared between different agencies or ministries. The roles and responsibilities of these government ministries may be quite different and duplication of responsibility and coordination of surveillance activities are common (Global Agricultural network Kenya, 2005). While food quality management systems have gained widespread attention, their effectiveness is questionable. Some studies (Wu \& Liu, 2010; Marin \& Ruiz-Olalla, 2011; Aldaihani \& Ali, 2018) claim that the implementation of these standards is beneficial to hospitality destinations while other studies (Morris, 2006; Taylor \& Taylor, 2004) doubt it. 
According to McCabe, Li \& Chen, (2016), the main structure of the choice of destination presents a seven stage decision process: need recognition, information searching, the choices evaluation, purchase, post-purchase evaluation, and finally, divestment. This implies that evaluative criteria are the desired outcomes from purchase and consumption, and are expressed in the form of preferred attributes. Therefore, unlike previous work emphasizing the overall effect of perceived quality on customer satisfaction, the purpose of this research is to determine the effect of food quality on customer choice of dining destinations in 4 and 5 star Hotels in Kenya.

\section{Statement of the Problem}

As the core product of commercial food service, food quality plays a pivotal role in the dining experience and is critical to the success of the restaurants at tourism destinations (Bujisic, Hutchinson, and Parsa, 2014; Bae, Slevitch and Tomas, 2018). Previous research indicated that customer dining destination is positively associated with their revisit intention (Ji et al., 2016, 2018). Thus, enhancing customer dining satisfaction is crucial for the survival and sustainability of hospitality destinations. Despite this importance, existing literature suggests that the food quality of customers is a key predictor of their dining satisfaction. Studies conducted in Africa and Kenya in particular (e.g. Ohiokpehai, 2003; Omemu \& Aderoju, 2008) did not adequately seek to understand how consumers choose their destination. Tunalioglu et al., 2012; Validi et al., 2014; Darkow et al., 2015) confirms that governments in Africa face a number of obstacles in implementing FQ compliance standards; Besides these, Kenya experiences major problems of non-compliance with basic FQ practices in local markets. The level of awareness among food producers is negligible (World Bank, 2015). In reference to the above, the objective of this research was to determine the effect of food quality on customer choice of dining destinations in 4 and 5 star Hotels in Kenya.

\section{Literature Review}

\section{Food Quality}

FQ attributes largely depend on the food type and the individual's food preference since food attributes that constitute quality and consumer's perceptions change over time (Shaharudin et al., 2011). Consumers, therefore, need to understand their own quality perception since it influences their purchasing decisions (Rijswijk \& Frewer, 2008). Many studies have confirmed that FQ attributes include; freshness of food, food presentation, food taste, variety and food temperature (Chamhuri \& Batt, 2015). On these researches only a few have been done with the crucial attributes of food quality in relation to customer satisfaction and behavioral intention (Shaharudin et al., 2011). Therefore, unlike previous work emphasizing the overall effect of perceived quality on customer satisfaction, this study focuses on the relationship between food quality perceptions and destination choice.

\section{Food Quality Assurance Systems}

As defined by Hoffman and Sandt (2012), food quality management is an integrated approach of achieving and sustaining high food quality output. A study by Owiti (2014), noted that in Kenya, most food processing companies experience a declined performance in terms of low sales revenue due to lack of effective quality management systems such as IS0 9001:2008. While quality management systems have gained widespread attention, their effectiveness is, nevertheless, still questionable. Even though Ha and Jang (2013)) 
recommends that the competitive capability of a hotel is created as a result of its quality practices, there is still, however, need to explore the specific quality management practices that influence destination's performance. Arendt et al., (2013) notes that many food processing firms often struggle to embrace effective quality management systems as a way of meeting customers' demands in the global market.

\section{Food Legislation in Kenya}

The national food safety and quality system in Kenya is managed by various statutory government agencies under different ministries (Kibe \& Wanjau, 2014). According to Hoffmann and Jones (2018), Kenya lacks a defined and published policy on FQ as part of a wider National Food and Nutrition Policy. FQ control agencies operate under the Ministries of Trade, Industrialization, Public Health and Sanitation, Livestock, fisheries Development, and Agriculture. The agencies handling quality include; Kenya Bureau of Standards (KEBS), Kenya Agricultural Research Institute (KARI), Kenya Plant Health Inspectorate Services (KEPHIS), Department of Public Health (DPH), Department of Veterinary Services (DVS), Kenya Dairy Board (KDB), and Horticultural Crops Development Authority (HCDA), among others. Despite these, Kenya experiences major problems of non-compliance with basic FQ standards (Oloo, 2010).

\section{Tourism in Kenya}

Kenya's tourism industry has experienced rapid growth in recent times, except for effects of the world economic crisis and political unrest, the industry contributes over $10 \%$ of gross domestic product, despite recent upheavals (Republic of Kenya, 2000). In this symbolic framework, tourism sector is depicted as being surrounded by various external constraining forces (Zhang, Chen \& $\mathrm{Hu}, 2019$ ).

There are critical issues and challenges affecting Kenya's competitiveness and sustainability as tourist destination. Despite periods of recovery such as 2004-2007 and 2010, prolonged poor performance has characterized the last two decades, raising the concern of key stakeholders. There appears to be systemic and strategic issues and challenges that may be undermining the competitiveness of Kenya's tourism industry. Among this challenges, FQ is one of the key challenges. However, the authenticity and quality of food has not been fully convinced as competitive advantages by most practitioners. Food quality, also enhances destination attractiveness, reinforces destination brand identity which has been regarded as strategic tools to promote the social and economic development of destinations (Bessière, 2013).

\section{Customer Destination Choice determinants}

In the service industry, consumers are motivated to research service products before purchase because they cannot experience them in advance (Cetin \& Walls, 2016). When consumers make purchasing decisions, they consider multiple cues simultaneously. These consist of central cues that are directly related to the product. Consumers are differently motivated by the stages of the purchasing process, which may result in simultaneous cues influencing different outcomes (Kim, and Tanford, 2019). For example, in the setting of online purchasing, online reviews serve as primary cues, as they provide a direct message about the service product quality. The price of a product serves as involvement, which determines the extent to which customers rely on central versus peripheral cues.

A few studies demonstrate the psychological effect of customer reviews on attitudes and purchasing decisions for restaurants (Lee \& Cranage, 2014; Zhang \& Hanks, 
2018). Previous research on online customer reviews reported that negative online restaurant reviews lead to changes in potential customers' attitudes and attributions (Lee \& Cranage, 2014).

Destination image has become a popular area of investigation among tourism researchers as it has been found to influence destination choice, satisfaction, and postpurchase behavior (Munhurruna et al., 2015; Zhang et al., 2014). To this end one can conclude that to ensure success for the positioning strategy of a destination, it is very much imperative that the image of the destination and the specific product attributes that satisfy the tourists should be identified.

The increasing interest in healthy living has contributed to an increase in the consumption of healthy food. Taking a closer look at this relationship, recent research in the casual restaurant sector suggests that health-related values have a direct and positive impact on behavior and purchase intentions (Jun et al., 2014). Similarly, Kim et al., 2013a, 2013b) found that perceptions of restaurant food healthiness indirectly affect consumer behavioral intentions via the mediating role of satisfaction. Thus, based on the extant perspective that concern for health can significantly affect consumer behavior, when healthy options are available:

Healthiness of food can also be the main factor that make customers choose destination Kim et al., 2019). However, Consumers primarily seek information in the prechoice stage and make the actual purchase in the choice stage. In the post-choice stage, they decide whether to maintain the relationship with the provider and make a repeat purchase (Kim et al., 2013). Guests undergoes through multiple cues to influence judgments in an online purchasing (Janiszewski \& Wyer, 2014).

One of the attribute that can potentially influence guest consumption decision is price. The decisions of what and where to eat may depend on the individual's financial budget. Despite involved health risks, consumers may purchase certain food products because of economic situation (Yang and Mattila, 2016). Burusnukul, Binkley, and Sukalakamala, (2011) on his study in "Understanding tourists' patronage of Thailand foodservice establishments established that unfamiliarity with local foods can present tourists with psychological risks (where so called Food Neophobia becomes a problem). Additionally, Consumption of familiar food is noted also as providing the psychological comfort of home. This is especially true for tourists in unfamiliar environments where they may seek food that is part of their normal daily routines in their home country. Destination food experience in an international destination allows tourists to explore and enjoy destination food and beverages for a unique and memorable experience. This experience can trigger revisit intention among tourists who savor destination foods, proving the potency of destination food as a new marketing tool for tourists on holiday (Kim, Seo \& Nurhidayati, 2019).

For customers of luxury restaurants, the value is more developed with utilitarian value represented by both functional and financial value, while experiential value is represented by hedonic and expressive value (Yang \& Mattila, 2016). Healthiness of food was also examined because restaurant customers are interested in healthy food choices (Kim et al., 2013). 


\section{Research Methodology}

\section{Sample Design and Data Collection}

A cross- sectional research design involving both descriptive and inferential statistical procedures was adopted in this study. The research was carried out in Nairobi city and Mombasa (South and North Coast). The study area was chosen because it has the potential Four and Five Star Hotels which were likely to have standardized systems in quality management and the area provided excellent destination choice for both Local and international customers. A total of 27 Food and beverage managers and 27 head chefs or Sous were purposively sampled as respondents to the study. This implies that the targeted staff-participants for the entire hotels were $54(27 \times 2=54)$. The total number of guests sampled were 1058 who were sampled based on 2016 data provided by the Kenya Tourism Board bed occupancy calculated at $49 \%$. Purposive sampling technique was used to select the expected number of employees, while simple random sampling was used to select the guests. For guest sampling (see table 1 below).

Table 1: Sample Size for Guests

\begin{tabular}{|c|c|c|c|c|c|}
\hline \multirow{18}{*}{ Nairobi region } & Sampled Hotels & $\begin{array}{l}\text { Bed } \\
\text { occupancy }\end{array}$ & $\begin{array}{l}\text { Average } \\
\text { Occupancy } \\
49 \%\end{array}$ & $\begin{array}{l}\text { Desired } \\
\text { sample size } \\
70 \%\end{array}$ & $\begin{array}{l}\text { Actual } \\
\text { Sample } \\
\text { size } n f\end{array}$ \\
\hline & Kempinski & 200 & 98 & 69 & 40 \\
\hline & Hemingway's & 45 & 22 & 15 & 9 \\
\hline & Sankara Nairobi & 156 & 76 & 54 & 31 \\
\hline & Fairmont Norfolk & 170 & 83 & 58 & 34 \\
\hline & Sarova Stanley & 217 & 106 & 74 & 44 \\
\hline & Radisson Blu & 271 & 133 & 93 & 55 \\
\hline & Dusit D2 & 101 & 49 & 35 & 20 \\
\hline & Crowne Plaza & 206 & 101 & 71 & 42 \\
\hline & Tribe Hotel & 137 & 67 & 47 & 28 \\
\hline & Ole Sereni Hotel & 134 & 66 & 46 & 27 \\
\hline & House of Wayne & 20 & 10 & 7 & 4 \\
\hline & Southern Sun & 212 & 104 & 73 & 43 \\
\hline & The Boma & 148 & 73 & 51 & 30 \\
\hline & Sarova Panafric & 162 & 79 & 56 & 33 \\
\hline & Weston Hotel & 205 & 100 & 70 & 41 \\
\hline & Fairview & 133 & 65 & 46 & 27 \\
\hline & Windsor Golf & 205 & 100 & 70 & 41 \\
\hline \multirow{11}{*}{$\begin{array}{l}\text { Mombasa region } \\
\text { (south coast, north } \\
\text { coast) }\end{array}$} & Leopard Beach & 145 & 71 & 50 & 29 \\
\hline & Voyager Beach & 236 & 116 & 81 & 48 \\
\hline & Marina English & 96 & 47 & 32 & 19 \\
\hline & Swahili Beach & 250 & 123 & 86 & 50 \\
\hline & Leisure Lodge & 253 & 124 & 86 & 51 \\
\hline & Whitesands hotel & 335 & 164 & 115 & 68 \\
\hline & Diamond Dream & 70 & 34 & 24 & 14 \\
\hline & Baobab Beach & 686 & 336 & 235 & 138 \\
\hline & Turtle Bay & 290 & 142 & 99 & 59 \\
\hline & Serena Beach Hotel & 164 & 80 & 56 & 33 \\
\hline & TOTAL & 5247 & 2569 & 1799 & 1058 \\
\hline
\end{tabular}

Quantitative data was analyzed using both descriptive and inferential analytical steps, which was mainly simple regression analysis. Descriptive statistics included means, percentages and frequency distributions, while for inferential analysis, the level of significance was considered to be $5 \%$. Thematic analysis was, on the other hand, used on qualitative data. 


\section{Descriptive Results}

\section{Results and Analysis}

Results from the study showed that majority of managers were aged between 41 and 50 years $(66.78 \%)$ with $50 \%$ having bachelor's degree. While for executive chefs, majority of the respondents were aged between 31 and $40(44.0 \%)$ with majority $(52 \%)$ having reached college level. However, for hotel guests, it was noted that majority of guests under the study were aged between 31 and $40(38.5 \%)$ with postgraduate degree (62.4\%).

Responses from the study confirmed that all managers agreed that they were aware of what entails food quality. By hotel management having the knowledge of what entails high food quality, proper mechanisms and/or suitable adjustments that attracts more guests can be formulated and implemented. This $100 \%$ awareness level of food quality was, thus, a point of strength for these star-rated hotels.

For hotel guests, food quality was an important factor while choosing their hotel destinations and the findings were summarized as shown in Table 2.

Table 2. Whether Food Quality is Important

\begin{tabular}{lll}
\hline Whether Food Quality is a Decision Factor & Count & Percent \\
\hline Yes & 521 & $98.9 \%$ \\
No & 6 & $1.1 \%$ \\
\hline
\end{tabular}

From Table 2, it can be observed that almost all the guests (98.9\%) agreed that food quality is one of the key factors to consider while deciding on which hotel to visit. This observation supported the researcher's decision of considering food quality as a vital variable that directly influences destination choices. It was presumed that those who did not consider food quality as a crucial factor while deciding on which hotel to visit constituted individuals who responded that they have other reasons for visiting the hotels other than taking a meal.

Important aspects of food quality considered in this study included taste, natural or organic, freshness, appearance, not being risky, good health guarantee, good condition and quality mark. Respondents were then asked to rate the level of importance of each of the identified aspects using a Five-Point Likert scale. Using the averages of the response ratings, a summary pie chart was obtained as shown in Figure 1

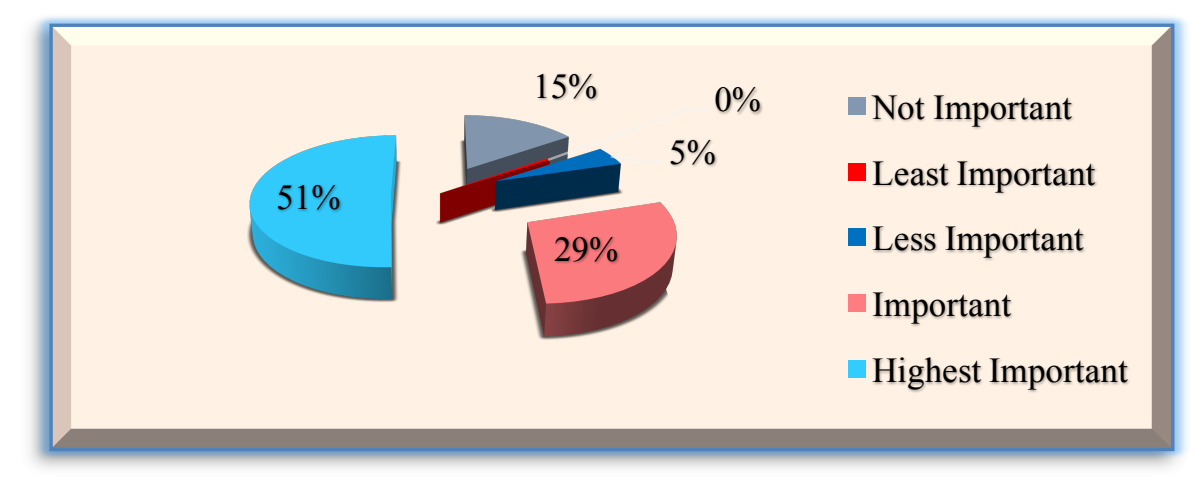

Figure 1 Compressed Responses on Various Aspects of Food Quality

From Figure 1, it can be observed that, on average, more than half of the respondents (51\%) agreed that the identified aspects were highly important. An interesting observation is made when we reduce the Five-Point Likert scale to Three-Point scale such that we have new categories "Important," "Less Important" and "Not Important." In this case, we would 
have the "Important" category with $80 \%$, "Less Important" category with $5 \%$ and "Not Important" category with $15 \%$. On the frequency and how the hotels conduct quality inspection, the responses were as follows

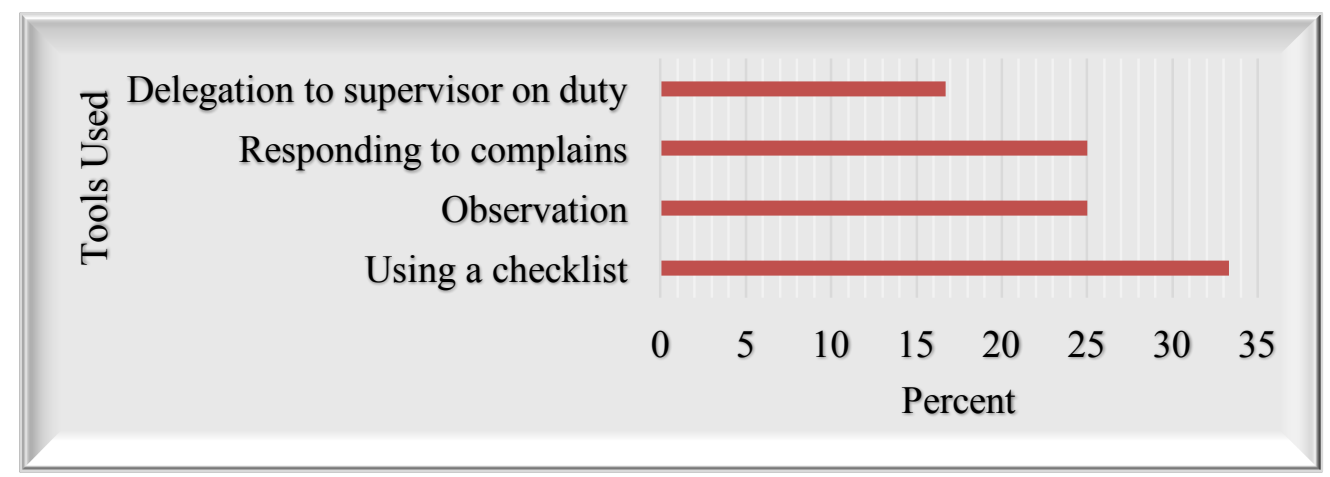

Figure 2: Frequency of Conducting Quality Inspections

From Figure 2, most hotels do conduct quality inspection quarterly and semi-annually, with each accounting for $37.5 \%$. Only $25 \%$ of the sampled hotels do conduct their quality inspections monthly. However, none of the hotels conduct their quality inspections annually. Despite absence of hotel that performs quality inspection annually, effective food monitoring and surveillance systems demand that the inspections should be conducted as frequent as possible. Success of such inspections is, nevertheless, pegged on tools used for monitoring and inspecting quality.

\section{Inferential Results}

To establish the effect of Food Quality (independent variable) on Dining Destination choice (dependent variable), a simple regression analysis was conducted. For this procedure, the corresponding regression model was

Destination Choice $=\boldsymbol{\beta}_{0}+\boldsymbol{\beta}_{1} \boldsymbol{F Q}+\boldsymbol{\varepsilon} \quad$ where FQ $=$ Food quality

The results for the regression analysis were as shown in Table 3 . 
Table 3: Direct Relationship Summary

\begin{tabular}{lccccc}
\hline \multicolumn{7}{c}{ Model Summary } \\
\hline $\mathrm{R}$ & $\mathrm{R}^{2}$ & Adjusted $\mathrm{R}^{2}$ & Std. Error & F Change & Sig. \\
\hline .708 & .501 & .489 & .517 & 4.906 & .025 \\
\hline \multicolumn{7}{c}{ Regression Coefficients } \\
\hline \multicolumn{7}{c}{ Beta } & Std. Error & t-statistics & Sig. \\
(Constant) & 9.275 & 7.321 & 1.267 & .065 \\
Food Quality & 1.392 & .331 & 4.205 & .045 \\
\hline \multicolumn{7}{c}{ ANOVA } \\
\hline \multicolumn{7}{c}{ df } & Mean Squares & F-statistics & Sig. \\
\hline Regression & Sum of Squares & df & 4.906 & .025 \\
Residual & 16.298 & 1 & 16.298 & \\
\hline Total & 43.186 & 13 & 3.322 & \\
\hline Dependent Variable: Customer Destination Choice \\
Predictors: (Constant), Food Quality
\end{tabular}

From Table 3, we observe that the R-squared is 0.489 which is $48.9 \%$ and the Fstatistic is 4.906 . The value of $R^{2}$ implies that the model explains only $48.9 \%$ variation in the dependent variables and the rest $51.1 \%$ is explained by factors not included in the model. That is, any variation in food quality only account for up to $48.9 \%$ of the variations in the customer dining destination choices. The remaining $51.1 \%$ is an indication that there are other predictor variables not included in the model but actively influences customer choice of dining destinations. The observed standard error for the coefficient of determination, $R^{2}$, was found to be 0.517 .

The overall effect of food quality was found to be significant since the corresponding -value for $R^{2}$ was 0.025 , which was less than 0.05 ( $\mathrm{P}$-value $=0.005<0.05$ ). Significance of this relationship can also be verified by checking whether the obtained model correctly fits the data using the results in the ANOVA section. It can be seen that the obtained F-ratio is significant with a corresponding P-value of $0.025(<0.05)$. This shows that the model is correct and it can, be used to test for the significance of the effect of food quality on the dependent variable (Destination choice). This is done using the results in the regression coefficients section, where all tests were done at $5 \%$ level of significance. In the regression coefficients section, the constant term was found to be 9.275. This term was, however, not significant at 5\% level since the corresponding P-value was greater than 0.05 $(0.065>0.05)$. It can be concluded that there is a significant relationship between food quality and customer's choice of dining destinations.

\section{Discussion}

Food quality plays a pivotal role in the dining experience and is critical to the success of the restaurants at tourism destinations (Bujisic, Hutchinson \& Parsa, 2014; Bae, Slevitch and Tomas, 2018). The main purpose of this study was to assess the relationship between food quality and customer choice on the dining destination in the Four- Five Star hotels in Kenya. Since almost all the guests $(98.9 \%)$ and all staffs agreed that food quality is one of the key factors to consider while deciding on which hotel to visit, this was, thus, a point of strength for the managers and executive chefs to effectively modify various aspects of food 
quality as a way of gaining a competitive advantage over other hotels. This observation is in agreement with the recommendation of Grunert (2005), Rohr et al. (2005) and Ha and Jang (2013). Further, this confirms Shaharudin et al., (2011)'s recommendation that in today's world, consumers have become more demanding, critical, and more fragmented in their food choices and food purchase decisions, which is largely influenced by food quality.

A similar study by Nordenskjöld, (2012), which involved regression modeling of destination satisfaction on local cuisines experience, had food quality as one of the independent variables. In this study, the overall model was found to be significant at 0.01 $(\mathrm{F}=47.738, \mathrm{p}<0.01)$ and in particular, food quality $(\beta=0.218, \mathrm{p}<0.01)$, positively affected the destination satisfaction of travelers. This finding therefore suggest that food quality is dominant attribute of consumer choice in dining destination choice through extant empirical evidence. That is, good quality food lead to destination selection while poor quality lead to rejection of the destination.

Moreover, Jae et al., (2015), while studying conflict of choice and how consumers choose where to go, confirmed that majority of respondents preferred the restaurant option with good quality food even if its price was relatively high compared to those who preferred utility gained from food quality to price. On the contrary, preference for service quality over price was not as strong as that for food quality.

\section{Conclusions and Recommendation}

There is indeed a strong relationship between food quality and customer choice of dining destination. Results of his study concluded that food quality is a key factors to consider while deciding on which hotel to visit. Apart from management the government should develop a holistic approach to quality management by designing initiatives that are aimed at improving quality in order to improve the effectiveness of a destination.

Hospitality management and the government should develop a holistic approach to quality management by designing and re-designing initiatives aimed specifically at the hospitality, and food sectors in order to improve quality products that exceeds customer expectations which will in turn result to customer's revisit intention. Based on these findings, this study recommends that although this study provided unique insights into the link between FQ and customer based factors to destination choice its conceptual and empirical setting had a number of limitations. This can be used as a source of future study.

\section{Research Limitations and Future Directions}

The study was carried out in Four and Five hotels in Kenya. Due to the sensitivity and the nature of the research, some Hotels did not give indepth information on the subject matter. In order to mitigate this, approval letter from the University was provided and earlier appointments with the hotels Managers made.

Questionnaires which were used for data collection where prompting and probing was needed was almost impossible and this limited the scope of answers and the possibility of getting additional data. Furthermore, interviews tool consumed much time in terms of preparation, scheduling, writing letters and booking appointments in a busy working environment like four and five star Hotels. In this case therefore key informants like managers did not have good quality time with the researcher. Many managers were relactant to provide information due to fear of the actual research intentions.

Based on these findings, this study recommends that although this study provided unique insights into the link between food quality to destination choice its conceptual and empirical setting 
had a number of limitations. For example, the study did not investigate the physical and chemical contamination that can cause unsafe food. Future studies and research can use this information as a source of future study.

\section{Acknowledgement}

Many thanks to God for granting me love, good health and an opportunity to pursue my studies at The Technical University of Kenya. My sincere gratitude goes to my supervisors Dr. Erick Fwaya and Dr. Methuselah Bichage, as well as Dr. Dunstan Kambaga for their continuous support and advice on this paper. I will also like to acknowledge the respondents particularly the Hotel Managers, chefs and Guests for their cooperation and giving essential information which was fundamental in this thesis. My sincere thanks to the Technical University Library for supporting me in getting research materials and information.

\section{References}

Ajiz, A. (2018). The predictors of tourists 'behavioral intention: the effect of destination image, perceived value and satisfaction (a case study of enshrinement complex of batujaya. Doctoral Dissertation, President University.

Aldaihani, F. M. F., \& Ali, N. A. (2018). Factors affecting customer loyalty in the restaurant service industry in Kuwait City, Kuwait. Journal of International Business and Management, 1(2), 1-14.

Arendt, S., Paez, P. \& Strohbehn, C. (2013). 'Food safety practices and managers' perceptions: a qualitative study in hospitality." International Journal of Contemporary Hospitality Management, 23 (1), 71-87.

Bae, S., Slevitch, L., \& Tomas, S. (2018). "The effects of restaurant attributes on satisfaction and return patronage intentions: Evidence from solo diners' experiences in the United States." Cogent Business \& Management, 5 (1), 1-16.

Bessière, J. (2013) 'Heritagisation', a challenge for tourism promotion and regional development: An example of food heritage. J. Herit. Tour., 8, 275-291.

Burusnukul, P., Binkley, M., \& Sukalakamala, P. (2011), "Understanding tourists' patronage of Thailand food service establishments", British Food Journal, 113 (8), $965-981$.

Caber, M., Yilmaz, G., Kiliçarslan, D., \& Öztürk, A. (2018), "The effects of tour guide performance and food involvement on food neophobia and local food consumption intention", International Journal of Contemporary Hospitality Management, 30 (3), 1472-1491.

Cetin, G., \& Walls, A. (2016). Understanding the customer experiences from the perspective of guests and hotel managers: Empirical findings from luxury hotels in Istanbul, Turkey. Journal of Hospitality Marketing \& Management, 25(4), 395-424.

Chamhuri, N., \& Batt, P., J. (2015). "Consumer perceptions of food quality in Malaysia. British Food Journal." Contemporary Hospitality Management, 28 (9), 1848-1867.

Darkow, I., L. (2015). "The involvement of middle management in strategy development-Development and implementation of a foresight-based approach." Technological Forecasting and Social Change, 101, 10-24.

Ha, J., \& Jang, S. (2013), "Determinants of diners ' variety seeking intentions", Journal of Services Marketing, 27 (2), 155-165.

Hoffmann, V., \& Jones, K. M. (2018). "Improving food safety on the farm: Experimental evidence from Kenya on agricultural incentives and subsidies as public health investments." Ifpri Discussion Paper, 1-61. Intention at restaurants: considering 
the role of attitudes toward taste and healthfulness of healthful foods", International Journal of Hospitality Management, Vol. 42, pp. 85-91.

Janiszewski, C., \& Wyer Jr, R. S. (2014). Content and process priming: A review. Journal of consumer psychology, 24 (1), 96-118.

Ji, M., Wong, I. A., Eves, A., \& Leong, A., W. (2018). "A multilevel investigation of China's regional economic conditions on co-creation of dining experience and outcomes", International Journal of Contemporary Hospitality Management, 30 (4), 2132-2152.

Jun, J., Kang, J. and Arendt, S.W. (2014), "The effects of health value on healthful food selection

Kibe, E. N., \& Wanjau, K. (2014). "The effect of quality management systems on the performance of food processing firms in Kenya." IOSR Journal of Business and Management, 16 (5), 61-72.

Kim, E. L., \& Tanford, S. (2019). Simultaneous effects of multiple cues in restaurant reviews. Journal of Services Marketing. 33 (5) 521-53.

Kim, H. J., Park, J., Kim, M. J., \& Ryu, K. (2013). Does perceived restaurant food healthiness matter? Its influence on value, satisfaction and revisit intentions in restaurant operations in South Korea. International Journal of Hospitality Management, 33, 397-405.

Kim, O. Y., Seo, S., \& Nurhidayati, V. A. (2019). Scale to measure tourist value of destination restaurant service. International Journal of Contemporary Hospitality Management. 31 (7) 2827-2844.

Lee, C. H., \& Cranage, D. A. (2014). Toward understanding consumer processing of negative online word-of-mouth communication: the roles of opinion consensus and organizational response strategies. Journal of Hospitality \& Tourism Research, 38(3), 330-360.

McCabe, S., Li, C., \& Chen, Z. (2016). "Time for a radical reappraisal of tourist decision making? Toward a new conceptual model." Journal of Travel Research, 55 (1), 315.

Ohiokpehai, Dorcus. M., D. \& Kamau, J. (2009). "The effects of soybean (Glycine max) and pigeon pea (Cajanuscajan) food mixtures on the nutritional status of school children in Suba District, Kenya." Journal of Food, Agriculture \& Environment JFAE. 7 (2), 59-63.

Oloo, J. (2010). Food Safety and Quality Management in Kenya: An Overview of the Roles Played by Various Stakeholders. African Journal of Food, Agriculture, Nutrition and Development, 10(11) 4379-4397.

Owiti, T. (2014). "Quality management practices and performance of hotels in Nairobi. Profiling Italian consumers." Appetite, 89 (1), 175-182.

Psomas, E. \& Kafetzopoulos, D. (2014). "Performance measures of ISO 9001 certified and non-certified manufacturing companies benchmarking." An International Journal, 21 (5), 756-774.

Republic of Kenya. (2000). Poverty Reduction Strategy Paper for the period 2001e2004. Nairobi.

Rowland, D., Ickowitz, A., Y., Powell, B., Nasi, R., \& Sunderland, T. (2017). "Forest foods and healthy diets: quantifying the contributions." Environmental Conservation, 44 (2), 102-114. 
Shaharudin, M., R., Ismail, A., S., Mansor, S., W., Elias, S., J., Jalil, M., A., \& Omar, M., W. (2011). "Innovative food and its effects toward consumers' purchase intention of fast food product." Canadian Social Science, 7 (1), 110-118.

Tunalioglu, R., Cobanoglu, F. \& Karaman, A., D. (2012), "Defining economic obstacles to the adoption of food safety systems in table olive processing firms", British Food Journal, 114 (10), 1486-1500.

Validi, S., Bhattacharya, A. \& Byrne, P. J. (2014). "A case analysis of a sustainable food supply chain distribution system - A multi-objective approach." International Journal of Production Economics, 2 (3), 1-3.

Wee, C., S., Ariff, M., Zakuan, N., Tajudin, M., Ismail, K., \& Ishak, N. (2014). "Consumers perception, purchase intention and actual purchase behavior of organic food products." Review of Integrative Business and Economics Research, 3 (2), 378-384.

Yang, W. and Mattila, A.S. (2016), "Why do we buy luxury experiences? Measuring value perceptions of luxury hospitality services", International Journal of Contemporary Hospitality Management, 28(9,) pp. 1848-1867. https://doi.org/10.1108/IJCHM-112014-0579

Zhang, L., \& Hanks, L. (2018). Online reviews: The effect of cosmopolitanism, incidental similarity, and dispersion on consumer attitudes toward ethnic restaurants. International Journal of Hospitality Management, 68, 115-123.

Zhang, T., Chen, J., \& Hu, B. (2019). Authenticity, quality, and loyalty: Local food and sustainable tourism experience. Sustainability, 11(12), 3437. 